Article

\title{
Polyimide Encapsulation of Spider-Inspired Crack-Based Sensors for Durability Improvement
}

\author{
Taewi Kim ${ }^{1,+}$, Taemin Lee ${ }^{2,3,+}$, Gunhee Lee ${ }^{2,3,+}$, Yong Whan Choi ${ }^{2,3,+}$, Sang Moon Kim ${ }^{4}$, \\ Daeshik Kang 1,* (i) and Mansoo Choi ${ }^{2,3, *}$ \\ 1 Department of Mechanical Engineering, Ajou University, San 5, Woncheon-Dong, Yeongtong-Gu, \\ Suwon 443-749, Korea; rlaxodnl@ajou.ac.kr \\ 2 Department of Mechanical and Aerospace Engineering, Seoul National University, Seoul 151-742, Korea; \\ nassxo@snu.ac.kr (T.L.); leepro2000@snu.ac.kr (G.L.); ccs08745@snu.ac.kr (Y.W.C.) \\ 3 Global Frontier Center for Multiscale Energy Systems, Seoul National University, Seoul 151-742, Korea \\ 4 Department of Mechanical Engineering, Incheon National University, Incheon 406-772, Korea; \\ ksm7852@inu.ac.kr \\ * Correspondence: dskang@ajou.ac.kr (D.K.); mchoi@snu.ac.kr (M.C.) \\ + These authors contributed equally to this work.
}

Received: 2 January 2018; Accepted: 1 March 2018; Published: 3 March 2018

\begin{abstract}
In mechanical sensory systems, encapsulation is one of the crucial issues to take care of when it comes to protection of the systems from external damage. Recently, a new type of a mechanical strain sensor inspired by spider's slit organ has been reported, which has incredibly high sensitivity, flexibility, wearability, and multifunctional sensing abilities. In spite of many of these advantages, the sensor is still vulnerable in harsh environments of liquids and/or high temperature, because it has heat-vulnerable polyethylene terephthalate (PET) substrate without any encapsulation layer. Here, we present a mechanical crack-based strain sensor with heat, water and saline solution resistance by alternating the substrate from polyester film to polyimide film and encapsulating the sensor with polyimide. We have demonstrated the ability of the encapsulated crack-based sensor against heat, water, saline solution damage through experiments. Our sensor exhibited reproducibility and durability with high sensitivity to strain (gauge factor above 10,000 at strain of two percent). These results show a new potential of the crack-based sensory system to be used as a wearable voice/motion/pulse sensing device and a high-temperature strain sensor.
\end{abstract}

Keywords: strain sensor; thin metal film; spider inspired; crack; encapsulation

\section{Introduction}

Sensor encapsulation is a crucial issue that needs to be taken care of in order to increase its applicability to various research fields. For example, bio-implantable devices, artificial skin, and wearable sensors need to endure wet and biochemical environments, and encapsulation of the device would guarantee the device performance [1-12]. Recently, a new type of mechanosensor inspired by a spider's sensory organ system has been reported, which includes nanoscale cracks on a metallic layer over a polymer substrate [13]. This spider-inspired sensor dramatically changes its electric resistance with the applied strain which widens the crack width. It also shows incredibly high sensitivity to strain with its extremely high gauge factor of over 2000 and vibration which is estimated to be measurable up to $10 \mathrm{~nm}$ amplitude [13]. The gauge factor (GF)—one of the most important indicators of the sensitivity of strain sensors-is defined as $G F=\left(\Delta R / R_{0}\right) / \varepsilon$. Where $\Delta R$ is the resistance change with deformation, $R_{0}$ is the resistance before deformation, and $\varepsilon$ is the applied deformation. Moreover, it has diverse advantages including flexibility, wearability, and multifunctional sensing abilities [13-17]. However, the durability of the sensor in harsh environments of liquids and/or high temperature is 
still a challenging issue. Sensor systems are usually exposed to various surrounding environments including different surrounding liquid, humidity and temperature, which lead to damage of the sensory system and shortening of the sensor's life. To solve this matter, we have demonstrated the extended capability of the crack sensory system by replacing the substrate from polyethylene terephthalate (PET) with polyimide (PI) and encapsulating the sensor with PI. Because the polyimide is widely used in flexible electronics or sensor systems due to its high durability and flexibility $[2,18,19]$, there are various advantages in applying our crack-based sensor system. Furthermore, Jonathan Viventi et al. has developed a device encapsulated with polyimide, demonstrating new opportunities for the sensors to be applied in clinical fields [20,21]. The encapsulated crack sensor can be used in diverse applications such as a wearable voice/pulse/motion sensor, strain gauge sensor at high temperature, vibration monitoring sensor for identifying internal damage to bridges, ultra-sensitive pressure/force sensor for surgical devices, and skin attachable health monitoring sensor.

\section{Experimental Section}

\subsection{The Fabrication of an Encapsulated Thin Metal Layered Crack Sensor}

The basic features of the encapsulated crack sensor are demonstrated in Figure 1a. The sensor was $5 \mathrm{~mm}$ in width and $50 \mathrm{~mm}$ in length, and the gauge length was $30 \mathrm{~mm}$. It was composed of five layers: $7.5 \mu \mathrm{m}$ thick PI film (3022-5 Kapton thin film, Chemplex, Palm City, FL, USA) or $6 \mu \mathrm{m}$ thick PET film (3026 Mylar thin film, Chemplex, Palm City, FL, USA) as the bottom substrate layer, $5 \mathrm{~nm}$ thick molybdenum trioxide $\left(\mathrm{MoO}_{3}\right)$ as an adhesion layer, $50 \mathrm{~nm}$ thick chromium $(\mathrm{Cr})$ as a crack inducing layer, $30 \mathrm{~nm}$ thick gold $(\mathrm{Au})$ for an electrical conductor, and lastly $650 \mathrm{~nm}$ thick cured polyimide film (Poly(pyromellitic dianhydride-co-4, $4^{\prime}$-oxydianiline), amic acid solution, Sigma-Aldrich, St. Louis, MO, USA ) on the top layer for the encapsulation of the total system. The PI precursor was spin-coated on the cracked metal films and it was cured on a hot plate in the $\mathrm{N}_{2}$ atmosphere $\left(80{ }^{\circ} \mathrm{C}\right.$ for $30 \mathrm{~min}$ and $290{ }^{\circ} \mathrm{C}$ for $\left.30 \mathrm{~min}\right) . \mathrm{MoO}_{3}$ is known as an adhesion layer between metal and polymer [17], and we simply tested it with "scotch tape test" [22]. It was confirmed that no defect occurred when the scotch tape was attached and detached on the metal surface (Figure S1t). The thin film layers $\left(\mathrm{MoO}_{3}\right.$, $\mathrm{Cr}$, and $\mathrm{Au}$ ) on the polymer substrate are deposited by the thermal evaporation system (Thermal Evaporation System, DD High Tech. Co., Gimpo-si, Gyeonggi-do, Korea). The thickness of deposited metals and polymers are measured by AFM (Atomic Force Microscopy) measurement.

a

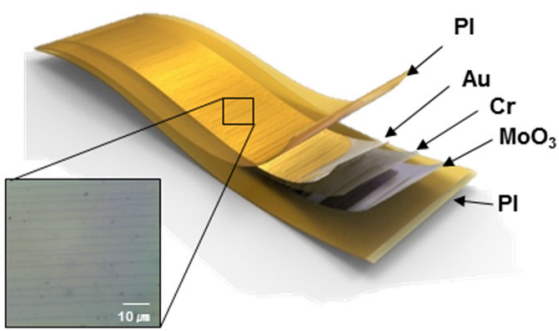

C

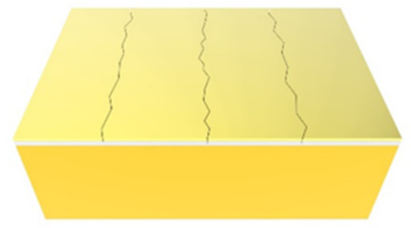

b

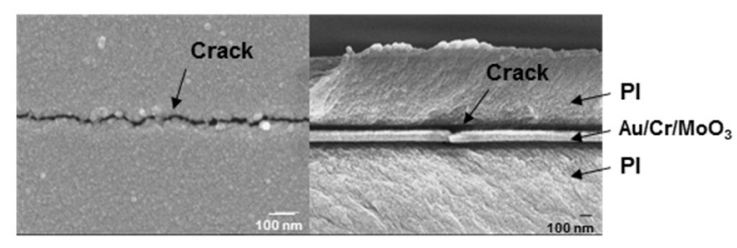

d

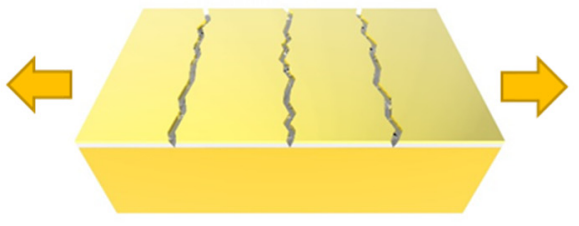

Figure 1. Schematic illustrations and scanning electron microscope (SEM) images of polyimide (PI) encapsulated crack sensor. (a) The schematic illustration and optical microscope image of the PI encapsulated crack sensor. (b) SEM image of the crack sensor before encapsulation (left), and cross-sectional SEM image after encapsulation (right). (c) The schematic illustration of generated cracks on metal layer before stretching. (d) The schematic illustration of widened cracks after stretching. 


\subsection{Thermal, Water, and Saline Solution Resistance Test}

To verify the performance of the device to detect vibration and strain in harsh environments such as liquid environment or a steam turbine blade, we tested the sensors in three different conditions (at high temperature, in water, and in saline solution). In these conditions, we also compared the sensors with three different types of substrates: sensors with a PET substrate without encapsulation, a PI substrate without encapsulation, and an encapsulated PI substrate. Each sensor was heated on a hot plate for $10 \mathrm{~min}$ at 100,200 and $300{ }^{\circ} \mathrm{C}$ and checked for each gauge factor by 50 cycles of straining from $0 \%$ to $2 \%$. For water and saline solution resistance tests, the sensors were dipped into water or saline solution for a certain period of time $(1,10,30 \mathrm{~h}$ for water resistance test and $12,24,36 \mathrm{~h}$ for saline solution resistance test) and checked for the gauge factor by 50 cycles of straining from $0 \%$ to $2 \%$ after being dried out in the ambient condition.

\subsection{Measuring Resistance Variation}

Figure S2 shows the experimental setup for measuring resistance variation by straining of the sensor. The sensors were stretched from $0 \%$ to $2 \%$ strains up to 15,000 times repeatedly with the sweeping speed of $20 \mathrm{~mm} / \mathrm{min}$ to measure the durability by using a material testing machine (3342 UTM, Instron Co., Norwood, MA, USA). The variation of resistance of the metal layered crack sensors was measured simultaneously by Lab View-based data acquisition system (PXI-4071, National Instruments Inc., Austin, TX, USA). Standard deviation of the measurement when measuring 2 wire resistance with $51 / 2$ digit was $0.01 \Omega$.

\section{Results and Discussion}

In general, metal layers on the crack lips can be delaminated by repetitive stretching, heating, and in water or chemical environments [23-32]. From repeated exposure to these environments, a sensor can have stress concentration on the edge due to different Poisson's ratio or thermal expansion mismatch $[23,25,33]$. A water or chemical environment causes degradation of the adhesion force between the metal film and the polymer substrate [32]. To measure the durability of our crack sensors, we have performed three kinds of experimental tests: thermal resistance test, water and saline solution resistance test, and marathon test.

In order to protect the crack sensor from the harsh environment and improve the durability, we encapsulated the crack-based sensor with PI. The schematic illustration of PI encapsulated crack-based sensor is presented in Figure 1a. The crack on the thin films was generated by stretching them at two-percent strain before encapsulation (Figure $1 \mathrm{~b}$ left). Additionally, the polyimide precursor solution was spin-coated on the thin cracked metal film. The cross-sectional SEM image (Figure $1 \mathrm{~b}$ right) shows that the solution does not penetrate into the gap of a crack because the gap was too narrow $(10-15 \mathrm{~nm})$. Figure 1c illustrates the cracks generated in the transverse direction to the extension force, and the crack gap increases with applied strain as shown in Figure 1d. The gauge factor of the encapsulated sensor reached above 10,000 at a strain of two percent with high reproducibility and durability.

The results in Figure 2 show that the thermal, water and saline solution durability of the crack sensor have been greatly improved with encapsulation by cured PI. In the thermal resistance test (Figure 2a), the PET substrate of the crack sensor maintained its gauge factor for about $90 \%$ at $200{ }^{\circ} \mathrm{C}$ because the deformation of the polymer surface reduced the stress concentration at the metal-polymer interface by going above glass-transition temperature $\left(T_{g}=85^{\circ} \mathrm{C}\right)$ [34]. However, it starts to break down when it is heated up to $300{ }^{\circ} \mathrm{C}$, exceeding the melting temperature of the PET $\left(\mathrm{T}_{\mathrm{m}}=290{ }^{\circ} \mathrm{C}\right)$ [35]. In the case of the PI substrate crack sensor without encapsulation, the relative GF rapidly decreased by heating, although the PI substrate was supposed to endure at the temperature above $300{ }^{\circ} \mathrm{C}$. This was due to the delamination caused by the different thermal expansion coefficient and weak adhesive force between the metal layer and the polymer substrate [36]. However, for the encapsulated crack 
sensor, the gauge factor remained at $77 \%$ even after heating at $300{ }^{\circ} \mathrm{C}$. The top encapsulating layer was responsible for enduring the heat treatment, which prevents the delamination of the metal layer from the substrate.
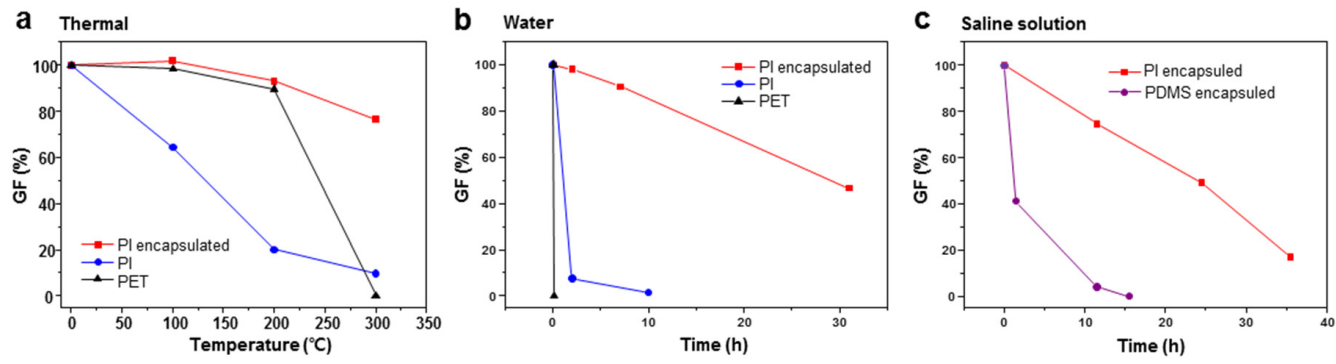

Figure 2. The performance comparison of the crack sensors in different environments. (a) Performances of the sensors after thermal treatment; (b) Performances of the sensors after dipping in water; (c) Performances of the sensors dipping in saline solution $(0.9 \% \mathrm{NaCl})$. PET: polyethylene terephthalate; PDMS: polydimethylsiloxane.

The graphs in Figure $2 \mathrm{~b}$ clearly show that sensors without encapsulation are very vulnerable in liquid environment. The metal layer of the PET substrate crack sensor delaminated as soon as it is immersed in water, and the PI substrate crack sensor also cannot resist liquid. However, the PI encapsulated crack sensor could endure $30 \mathrm{~h}$ in water and $24 \mathrm{~h}$ in $0.9 \%$ saline water with the gauge factor of two-percent strain even though the relative gauge factor decreased to $50 \%$. However, we could see that straining two percent in a state where the adhesion force was degraded due to wet conditions accelerated degradation of its gauge factor. Figure S3 shows that when the strain range was from zero to one percent, the sensor maintains its GF of $90 \%$ or more for $130 \mathrm{~h}$, and Figure S4 shows that there was no base resistance change for $190 \mathrm{~h}$ without straining. Because the actual operating range of the sensor would not be higher than one percent, it could endure longer in a wet environment.

Figure 2c, PI is also verified as a very good passivation layer compared with PDMS (PDMS: polydimethylsiloxane) by its water permeability. Compared to a sensor encapsulated with a PDMS of $30 \mu \mathrm{m}$ thickness, it showed superior performance in saline solution. The major cause of GF decreases in liquid environment is delamination. In Figure S5, the PI or PDMS encapsulated crack sensor immersed in saline solution shows that the metal layer is separated from the substrate, which indicates an increase of the base line. However, the delamination issue in these environments can be enhanced by a thicker encapsulation layer. Figure $3 \mathrm{c}$ shows that if the thickness of the encapsulation layer is increased to $10 \mu \mathrm{m}$, it can last more than $100 \mathrm{~h}$ in saline solution, but it must be appropriately adjusted because it is in a trade-off relationship with the sensitivity of the sensor (Figure 3a,b). These results show a large expandability of the crack sensor in a humid environment, such as a wearable device.
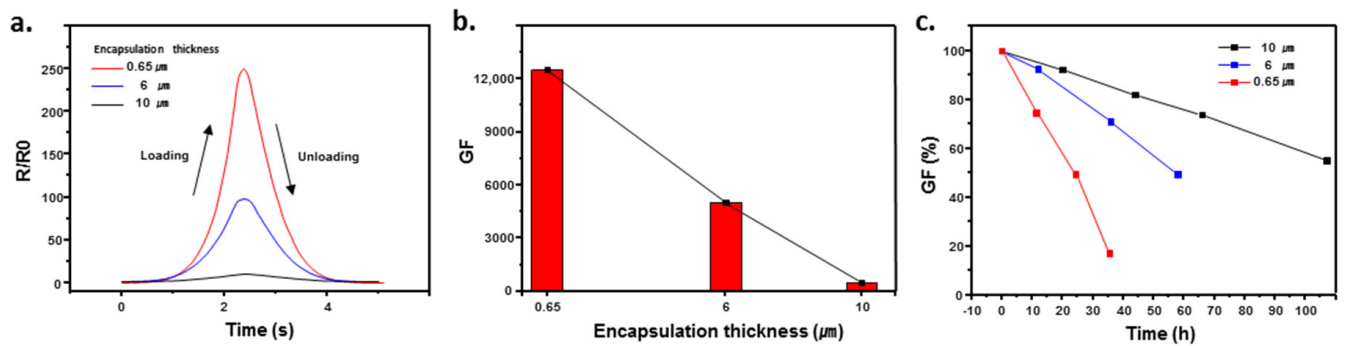

Figure 3. Comparison of performance changes according to PI encapsulation thickness. (a) Resistance response in two-percent strain for various encapsulation thicknesses. (b) Gauge factor comparison by encapsulation thickness. (c) Performance comparison by encapsulation thickness in saline solution $(0.9 \% \mathrm{NaCl})$. 
Figure 4 shows durability (marathon test) performance of the sensors up to 15,000 cycles. First, the crack sensor on PET substrate without the encapsulating layer lost its gauge factor rapidly by $20 \%$ from the first 1000 to 15,000 cycles of repetitive stretching (Figure $4 a$ ). Second, the GF of the crack sensor on PI substrate without the encapsulating layer increased until 3000 cycles and started to decrease gradually until 7000 cycles, and it became $30 \%$ of maximum GF at 15,000 cycles (Figure $4 \mathrm{~b}$ ). The reason why the sensitivity increased first and then decreased was that deepening of crack depth by penetration and incomplete recovery of crack gap by residual stress occurred simultaneously. When a crack penetrates into the substrate, sensitivity increases by deepening the crack depth [16]. However, repetitive straining accumulates residual stress on the crack vertex, disturbing closing of the crack gap, causing the gauge factor to decrease [37]. Third, the crack sensor on PI substrate with the encapsulating layer had lower sensitivity than that of the crack sensor on PI substrate without encapsulation, but sensitivity drop with repeated tensile load improved slightly. It maintains its GF above $65 \%$ until 11,000 cycles (Figure 4c). These results show that the encapsulating layer contributes to delay of the progress of the crack.

a

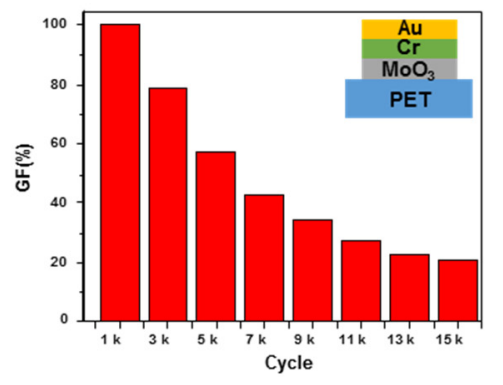

b

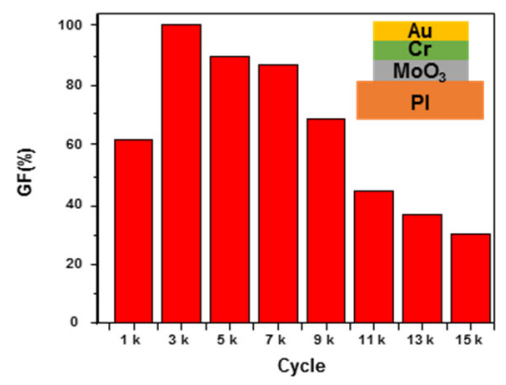

c

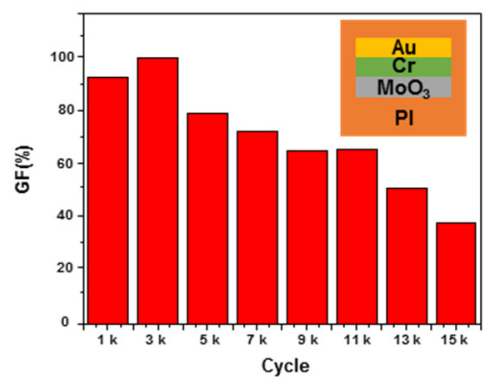

Figure 4. Marathon test of the crack sensors up to 15,000 cycles. (a) Durability test result of the crack sensor on PET substrate. (b) Durability test result of the crack sensor on PI substrate. (c) Durability test result of the PI encapsulated crack sensor on PI substrate.

The resistance of the metal films on the polymer substrate dramatically increases due to the crack gap opening by stretching it up to two percent. To use it as a sensor, the reverse process should return the initial crack gap and its initial resistance as well. Figure 5a-c show that a 10-cycle set of strains from zero to two percent at a sweeping speed of $20 \mathrm{~mm} / \mathrm{min}$ with one second of the interval was nearly identical. The linearly fitted gauge factor of crack sensor on PET substrate with the strain range from zero to two percent by regression analysis was $\sim 2800$, that of the crack sensor on PI substrate was 28,000 , and that of the PI encapsulated crack sensor was 12,500. Interestingly, it shows that by only changing substrates from PET to PI, sensitivity increased up to 10 times. We assume that this phenomenon was caused by crack penetration into the PI substrate because the sensitivity of the sensor increases as the depth of crack increases [16]. Figure S6+ shows the change in resistance of three samples when applied strain from zero to two percent. The result demonstrates that the change in resistance to the applied strain of the PI encapsulated crack sensor was more linear than the other sensors. However, the PI encapsulation process induced reduced gauge factor of $\sim 45 \%$. Figure $5 \mathrm{~d}-\mathrm{f}$ each shows a graph of the averaged normalized resistance of three different samples along with an error bar $(n=5)$. Black square marks are for the loading to the strain of two percent, and red circle marks are for unloading. The response time of the sensor was about five milliseconds (Figure S7t). It shows that these three different types of sensors had quite good reproducibility without hysteresis. 
a

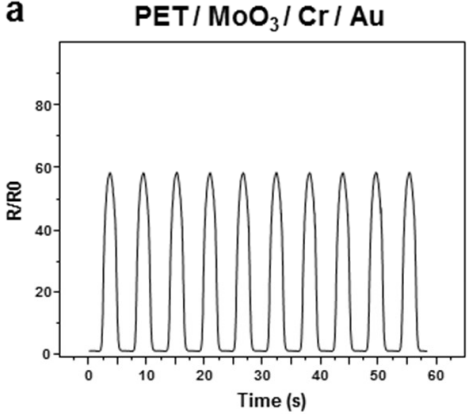

d

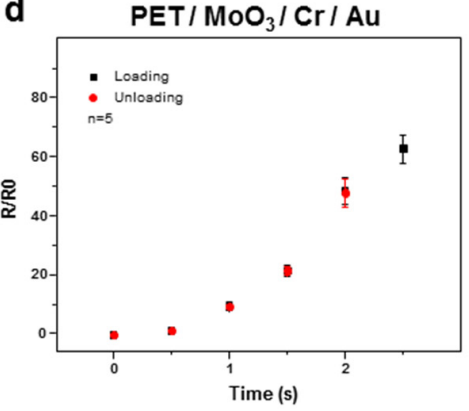

b

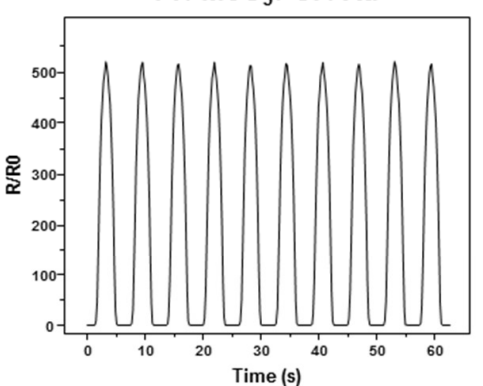

e

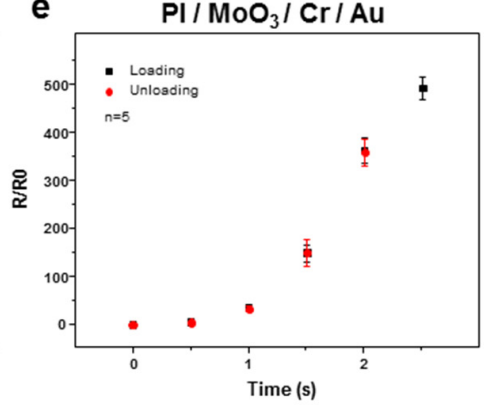

C

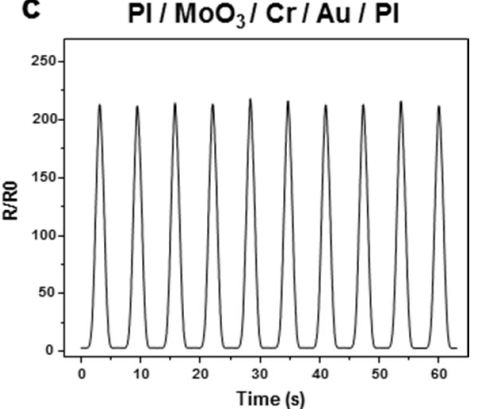

f

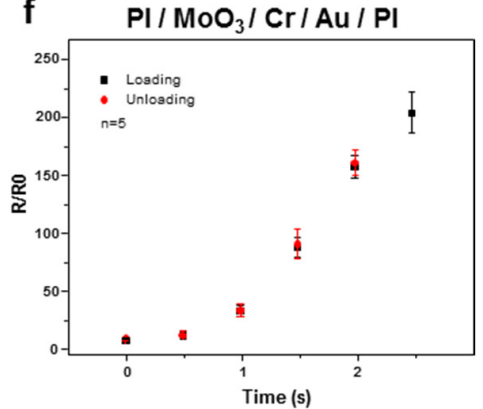

Figure 5. The normalized resistance variations of the crack sensors with strain. (a) The normalized resistance variance versus two-percent strain in 10 times cyclic test of the crack sensor on PET substrate. (b) The crack sensor on PI substrate without the encapsulating layer. (c) The crack sensor on PI substrate with the encapsulating layer. (d) Reproducible and hysteresis test obtained from crack sensors on PET substrate. (e) Crack sensors on PI substrate without the encapsulating layer. (f) The crack sensors on PI substrate with the encapsulating layer.

\section{Conclusions}

We have demonstrated that the PI encapsulated crack sensor can operate in a harsh environment such as heat, water, and saline solution. After deposition of $\mathrm{MoO}_{3}, \mathrm{Cr}$, and $\mathrm{Au}$ on the thin polyimide film, the crack was generated by stretching, and lastly, the sample was covered with a PI solution and cured on a hot plate. Several advantages of encapsulation of the crack sensor-thermal resistance, water/saline solution resistance, and durability—were verified by experiments. The results represent that the thermal, water and saline solution resistances were improved by encapsulation. Concretely, the encapsulated sensor is heat-endurable even at $300{ }^{\circ} \mathrm{C}$, water-resistible for $30 \mathrm{~h}$, and saline solution-endurable for $24 \mathrm{~h}$ with the gauge factor of two-degree strain. These results show its capability to be used as an wearable device and strain gauge at high temperature.

Supplementary Materials: The following are available online at http:/ / www.mdpi.com/2076-3417/8/3/367, Figure S1: Scotch tape test with an adhesion force of $4.5 \mathrm{~N} / 25 \mathrm{~mm}$ for PI substrate crack sensor (reference number of 600, 3 M), Figure S2: Experimental set up for measuring resistance variation, Figure S3: The performance degradation by dipping into water, Figure S4: Base line shift by dipping into water without straining, Figure S5: Delamination of metal film due to penetration of saline solution, Figure S6: Strain-response curve of crack sensors, Figure S7: The response time of the encapsulated crack based sensor.

Acknowledgments: Daeshik Kang and Sang Moon Kim acknowledge financial support by Basic Science Research Program through the National Research Foundation of Korea (NRF) funded by the Ministry of Science, ICT \& Future Planning (2016R1C1B1009689 and 2016R1C1B1014564). Daeshik Kang acknowledges financial support by the new faculty research fund of Ajou University, the Ajou University research fund and the Nature-Inspired Innovative Technology Development Program through the National Research Foundation of Korea (NRF), which is funded by the Ministry of Science and ICT (NRF-2017M3C1B7014222). Mansoo Choi acknowledges financial support by the Global Frontier R\&D Program of the Center for Multiscale Energy Systems (No. 2012M3A6A7054855) funded by the National Research Foundation (NRF) of Korea. 
Author Contributions: Daeshik Kang, and Mansoo Choi conceived and designed the experiments; Taewi Kim, Taemin Lee, Gunhee Lee, and Yong Whan Choi performed the experiments; Taewi Kim, Taemin Lee, and Yong Whan Choi analyzed the data; Taewi Kim, Gunhee Lee, Sang Moon Kim, and Daeshik Kang wrote the paper.

Conflicts of Interest: The authors declare no conflict of interest.

\section{References}

1. Kinkeldei, T.; Munzenrieder, N.; Zysset, C.; Cherenack, K.; Tröster, G. Encapsulation for flexible electronic devices. IEEE Electron Device Lett. 2011, 32, 1743-1745. [CrossRef]

2. Kim, D.-H.; Ghaffari, R.; Lu, N.; Rogers, J.A. Flexible and stretchable electronics for biointegrated devices. Annu. Rev. Biomed. Eng. 2012, 14, 113-128. [CrossRef] [PubMed]

3. Kim, D.-H.; Lu, N.; Ghaffari, R.; Kim, Y.-S.; Lee, S.P.; Xu, L.; Wu, J.; Kim, R.-H.; Song, J.; Liu, Z. Materials for multifunctional balloon catheters with capabilities in cardiac electrophysiological mapping and ablation therapy. Nat. Mater. 2011, 10, 316-323. [CrossRef] [PubMed]

4. Kim, D.-H.; Lu, N.; Huang, Y.; Rogers, J.A. Materials for stretchable electronics in bioinspired and biointegrated devices. MRS Bull. 2012, 37, 226-235. [CrossRef]

5. Wagner, S.; Bauer, S. Materials for stretchable electronics. MRS Bull. 2012, 37, 207-213. [CrossRef]

6. Choi, M.-C.; Kim, Y.; Ha, C.-S. Polymers for flexible displays: From material selection to device applications. Prog. Polym. Sci. 2008, 33, 581-630. [CrossRef]

7. Kim, D.H.; Liu, Z.; Kim, Y.S.; Wu, J.; Song, J.; Kim, H.S.; Huang, Y.; Hwang, K.C.; Zhang, Y.; Rogers, J.A. Optimized structural designs for stretchable silicon integrated circuits. Small 2009, 5, 2841-2847. [CrossRef] [PubMed]

8. Chung, H.J.; Sulkin, M.S.; Kim, J.S.; Goudeseune, C.; Chao, H.Y.; Song, J.W.; Yang, S.Y.; Hsu, Y.Y.; Ghaffari, R.; Efimov, I.R. Stretchable, multiplexed $\mathrm{pH}$ sensors with demonstrations on rabbit and human hearts undergoing ischemia. Adv. Healthc. Mater. 2014, 3, 59-68. [CrossRef] [PubMed]

9. Xu, S.; Zhang, Y.; Jia, L.; Mathewson, K.E.; Jang, K.-I.; Kim, J.; Fu, H.; Huang, X.; Chava, P.; Wang, R. Soft microfluidic assemblies of sensors, circuits, and radios for the skin. Science 2014, 344, 70-74. [CrossRef] [PubMed]

10. Atalay, O.; Atalay, A.; Gafford, J.; Wang, H.; Wood, R.; Walsh, C. A highly stretchable capacitive-based strain sensor based on metal deposition and laser rastering. Adv. Mater. Technol. 2017, 2. [CrossRef]

11. Lee, J.; Kim, S.; Lee, J.; Yang, D.; Park, B.C.; Ryu, S.; Park, I. A stretchable strain sensor based on a metal nanoparticle thin film for human motion detection. Nanoscale 2014, 6, 11932-11939. [CrossRef] [PubMed]

12. Wang, Y.; Wang, L.; Yang, T.; Li, X.; Zang, X.; Zhu, M.; Wang, K.; Wu, D.; Zhu, H. Wearable and highly sensitive graphene strain sensors for human motion monitoring. Adv. Funct. Mater. 2014, 24, 4666-4670. [CrossRef]

13. Kang, D.; Pikhitsa, P.V.; Choi, Y.W.; Lee, C.; Shin, S.S.; Piao, L.; Park, B.; Suh, K.-Y.; Kim, T.-I.; Choi, M. Ultrasensitive mechanical crack-based sensor inspired by the spider sensory system. Nature 2014, 516, 222-226. [CrossRef] [PubMed]

14. Choi, Y.W.; Kang, D.; Pikhitsa, P.V.; Lee, T.; Kim, S.M.; Lee, G.; Tahk, D.; Choi, M. Ultra-sensitive pressure sensor based on guided straight mechanical cracks. Sci. Rep. 2017, 7, 40116. [CrossRef] [PubMed]

15. Lee, T.; Choi, Y.W.; Lee, G.; Pikhitsa, P.V.; Kang, D.; Kim, S.M.; Choi, M. Transparent ITO mechanical crack-based pressure and strain sensor. J. Mater. Chem. C 2016, 4, 9947-9953. [CrossRef]

16. Park, B.; Kim, J.; Kang, D.; Jeong, C.; Kim, K.S.; Kim, J.U.; Yoo, P.J.; Kim, T.I. Dramatically enhanced mechanosensitivity and signal-to-noise ratio of nanoscale crack-based sensors: Effect of crack depth. Adv. Mater. 2016, 28, 8130-8137. [CrossRef] [PubMed]

17. WhanáChoi, Y.; MoonáKim, S. Crack-based strain sensor with diverse metal films by inserting an inter-layer. RSC Adv. 2017, 7, 34810-34815.

18. Van den Brand, J.; De Kok, M.; Koetse, M.; Cauwe, M.; Verplancke, R.; Bossuyt, F.; Jablonski, M.; Vanfleteren, J. Flexible and stretchable electronics for wearable health devices. Solid-State Electron. 2015, 113, 116-120. [CrossRef] 
19. Takei, K.; Takahashi, T.; Ho, J.C.; Ko, H.; Gillies, A.G.; Leu, P.W.; Fearing, R.S.; Javey, A. Nanowire active-matrix circuitry for low-voltage macroscale artificial skin. Nat. Mater. 2010, 9, 821-826. [CrossRef] [PubMed]

20. Viventi, J.; Kim, D.-H.; Vigeland, L.; Frechette, E.S.; Blanco, J.A.; Kim, Y.-S.; Avrin, A.E.; Tiruvadi, V.R.; Hwang, S.-W.; Vanleer, A.C. Flexible, foldable, actively multiplexed, high-density electrode array for mapping brain activity in vivo. Nat. Neurosci. 2011, 14, 1599-1605. [CrossRef] [PubMed]

21. Viventi, J.; Kim, D.-H.; Moss, J.D.; Kim, Y.-S.; Blanco, J.A.; Annetta, N.; Hicks, A.; Xiao, J.; Huang, Y.; Callans, D.J. A conformal, bio-interfaced class of silicon electronics for mapping cardiac electrophysiology. Sci. Transl. Med. 2010, 2, 24ra22. [CrossRef] [PubMed]

22. Byun, I.; Coleman, A.W.; Kim, B. Transfer of thin au films to polydimethylsiloxane (PDMS) with reliable bonding using (3-mercaptopropyl) trimethoxysilane (MPTMS) as a molecular adhesive. J. Micromech. Microeng. 2013, 23, 085016. [CrossRef]

23. Dauskardt, R.; Lane, M.; Ma, Q.; Krishna, N. Adhesion and debonding of multi-layer thin film structures. Eng. Fract. Mech. 1998, 61, 141-162. [CrossRef]

24. Waters, P.; Volinsky, A. Stress and moisture effects on thin film buckling delamination. Exp. Mech. 2007, 47, 163-170. [CrossRef]

25. Alaca, B.E.; Saif, M.; Sehitoglu, H. On the interface debond at the edge of a thin film on a thick substrate. Acta Mater. 2002, 50, 1197-1209. [CrossRef]

26. Yu, H.-H.; He, M.; Hutchinson, J. Edge effects in thin film delamination. Acta Mater. 2001, 49, 93-107. [CrossRef]

27. Miller, R.A.; Lowell, C.E. Failure mechanisms of thermal barrier coatings exposed to elevated temperatures. Thin Solid Films 1982, 95, 265-273. [CrossRef]

28. Wiklund, U.; Gunnars, J.; Hogmark, S. Influence of residual stresses on fracture and delamination of thin hard coatings. Wear 1999, 232, 262-269. [CrossRef]

29. Evans, A.; He, M.; Hutchinson, J. Mechanics-based scaling laws for the durability of thermal barrier coatings. Prog. Mater. Sci. 2001, 46, 249-271. [CrossRef]

30. Evans, A.; Hutchinson, J. The mechanics of coating delamination in thermal gradients. Surf. Coat. Technol. 2007, 201, 7905-7916. [CrossRef]

31. Hutchinson, J.; Evans, A. On the delamination of thermal barrier coatings in a thermal gradient. Surf. Coat. Technol. 2002, 149, 179-184. [CrossRef]

32. Leung, S.Y.; Lam, D.C.C.; Luo, S.; Wong, C. The role of water in delamination in electronic packages: Degradation of interfacial adhesion. J. Adhes. Sci. Technol. 2004, 18, 1103-1121. [CrossRef]

33. Martena, M.; Botto, D.; Fino, P.; Sabbadini, S.; Gola, M.; Badini, C. Modelling of TBC system failure: Stress distribution as a function of TGO thickness and thermal expansion mismatch. Eng. Fail. Anal. 2006, 13, 409-426. [CrossRef]

34. Koros, W.; Paul, D. Transient and steady-state permeation in poly (ethylene terephthlate) above and below the glass transition. J. Polym. Sci. Part B Polym. Phys. 1978, 16, 2171-2187. [CrossRef]

35. Groeninckx, G.; Reynaers, H.; Berghmans, H.; Smets, G. Morphology and melting behavior of semicrystalline poly (ethylene terephthalate). I. Isothermally crystallized pet. J. Polym. Sci. Part B Polym. Phys. 1980, 18, 1311-1324. [CrossRef]

36. Ghosh, M. Polyimides: Fundamentals and Applications; CRC Press: Boca Raton, FL, USA, 1996.

37. Park, B.; Lee, S.; Choi, H.; Kim, J.U.; Hong, H.; Jeong, C.; Kang, D.; Kim, T.-I. Semi-permanent and durable nanoscale-crack-based sensor by on-demand healing. Nanoscale 2018. [CrossRef] [PubMed]

(C) 2018 by the authors. Licensee MDPI, Basel, Switzerland. This article is an open access article distributed under the terms and conditions of the Creative Commons Attribution (CC BY) license (http://creativecommons.org/licenses/by/4.0/). 